\title{
Synthesis of Conjugated Polymer Film by Electrolytic Polymerisation in Lyotropic Liquid Crystal
}

\author{
Naoto Eguchi ${ }^{1}$, Hiromasa Goto ${ }^{2, *}$ \\ ${ }^{1}$ College of Engineering Sciences, University of Tsukuba, University of Tsukuba, \\ Tsukuba, Ibaraki 305-8573, Japan \\ ${ }^{2}$ Division of Materials Science, Faculty of Pure and Applied Sciences, University of Tsukuba, \\ Tsukuba, Ibaraki 305-8573, Japan \\ *E-mail address: gotoh@ims.tsukuba.ac.jp
}

\begin{abstract}
We prepared lyotropic liquid crystal by using disodium cromogrycate that shows liquid crystal by dissolving in water. Next, we added monomer to the prepared solution, and electrolyic polymerisation was carried out. Finally, we obtained a conductive thin polymer film. This result shows that lyotrpic liquid crystal can be used for matrix.
\end{abstract}

Keywords: Liquid crystal; Lyotropic; Conductive polymer; Biology; Self-organization

\section{INTRODUCTION}

Since it was known that polyacetylene which shows conductivity for the first time by doping, the study on conjugated system polymer has been studyed actively. One of the conductive polymers 'polypyrrole' has been applied for an electrolytic capacitor as a rechargeable battery [1]. We can see lyotropic liquid crystal tissue in living organisms. For example, lipid double layer occupied most of the cell membrane.

The phosphatide molecules form double layer structure through self-organisation with a surfactant character. Furthermore, proteins such as ion channels have fluidity. These biomaterials show lyotoropic liquid crystallinity having both fluidity and ordering characteristics. Self-organisation of the lipid double layers is also important property for maintaining their cirtain form in the living system. In the previous work, chiral conjugated polymers were synthesised by electrochemical polymerisation in a cholesteric-liquid-crystal electrolyte [2,3]. Here, we consider that conductive polymer film can be prepared in bio-liquid crystals as a template. As the first step, we perform electrolytic polymerisation in a lyotropic liquid crystal in this study.

Disodium cromogrycate as a lyotropic liquid crystal molecule is employed for it. This compound has been typically used as an antiallergic drug. This lytropic liquid crystal state is assumed to be an analog of biological system. 


\section{EXPERIMENT}

\section{1. Preparation of lyotropic liquid crystal}

Disodium cromoglycate was dissolved in water at room temperature. The vial was heated, and gradually cooled to room temperature.

L-tryptophan methyl ester was added to induce cholesteric phase (Figure 1). Tetrabutyl ammonium perchlorate was further as a supporting salt.

\section{2. Chemical structures}

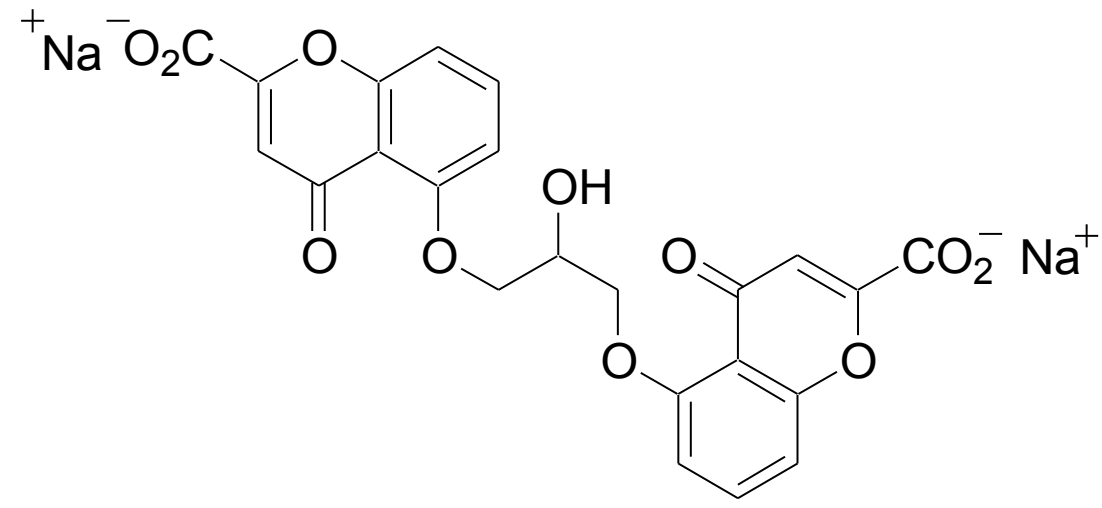

${ }^{1}$ Disodium Cromogrycate

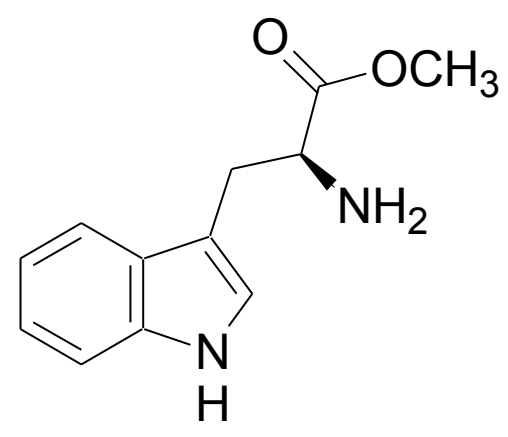

${ }^{2}$ L-tryptophan methyl ester

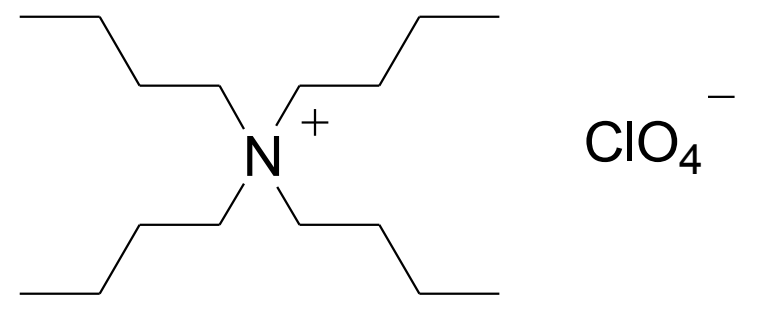

${ }^{3}$ Tetrabutyl ammonium Perchlorate 


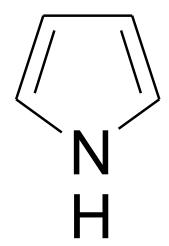

${ }^{4}$ Pyrrole

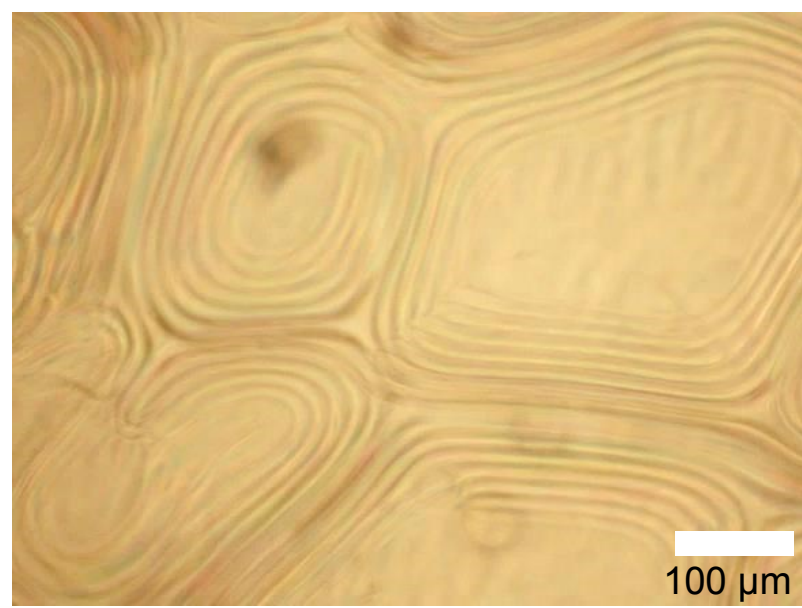

Figure 1. Polarising optical microscopy image of cholesteric lyotrioic liquid crystal.

Table 1. constituents of solution.

\begin{tabular}{ccccc}
\hline $\begin{array}{c}\text { Water } \\
(\mathrm{mL})\end{array}$ & $\begin{array}{c}\text { Disodium }^{1}(\mathrm{mg}) \\
\text { Cromogrycate }^{1}\left(\begin{array}{c}\text { L-tryptophan methyl } \\
\text { ester }^{2}(\mathrm{mg})\end{array}\right.\end{array}$ & $\begin{array}{c}\text { Tetrabutyl ammonium } \\
\text { Perchlorate }^{3}(\mathrm{mg})\end{array}$ & Pyrrole $^{4}$ \\
\hline 1 & 400 & 1 & 11 & $0.02(\mathrm{~mL})$ \\
\hline
\end{tabular}

\section{3. Polymerisation in lyotropic liquid crystal}

Electrolytic polymerisation was carried out by applying voltage of $2.5 \mathrm{~V}$ at room temperature for 10 minutes (Scheme 1). This polymerisation process was carried out by using a sandwich cell with $0.2 \mathrm{~mm}$ Teflon spacer. After electrolytic polymerisation, thin polymer film on anode side was washed by water and dried (Figure 2).
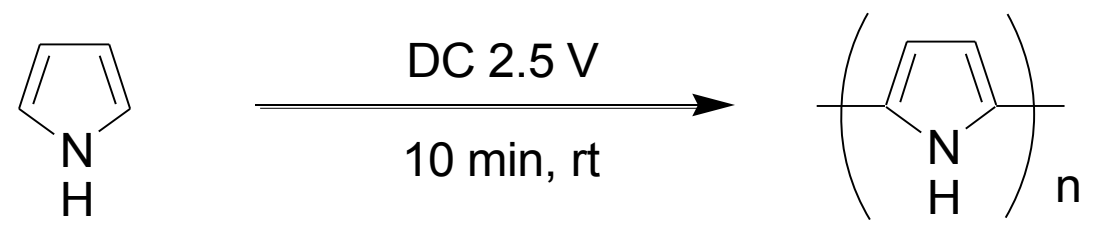

Scheme 1. Electrolytic polymerisation. 


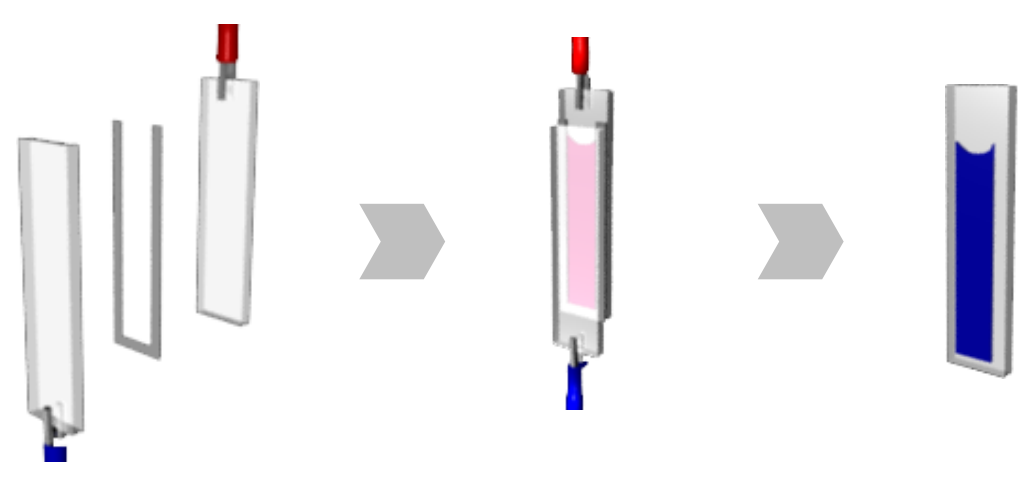

Figure 2. Schematic diagram of electrolytic polymerisation.

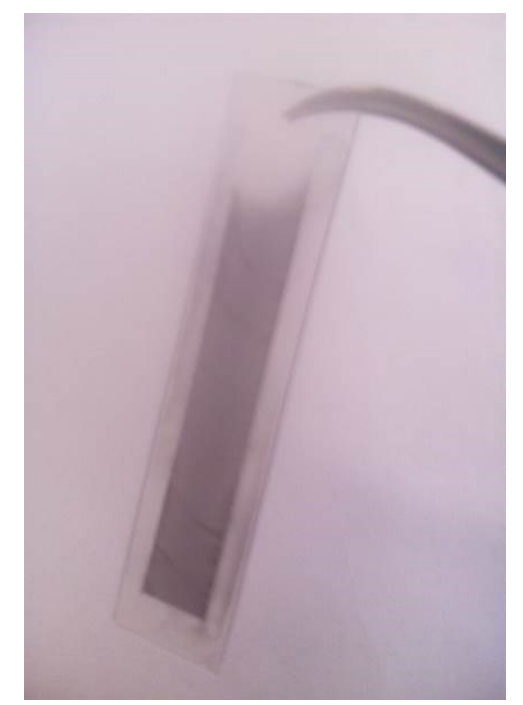

Figure 3. Polyoyrrole film synthesised in lyotropic liquid crystal.

\section{CONCLUSION}

We prepared cholesteric lyotropic liquid crystal. Next, electrolytic polymerisation was carried out in the lyotropic liquid crystal solution. We obtained a thin conductive polymer film (Figure 3). However, fingerprint texture derived from cholesteric phase was not observed in this research.

This result suggests a potential of synthesis in the living organisms showing lyotropic liquid crystal. A film may perform biological function if we can achieve polymerisation in the living system and transcribe the living tissue into the polymer film. 


\section{References}

[1] Y. Kudoh, M. Fukuyama S. Yoshimura, Synth. Met. 66 (2007) 253901.

[2] H. Goto, Phys. Rev. Lett. 98 (2007) 253901.

[3] H. Goto, Macromolecules 40 (2007) 13771385. 